\title{
DO DIÁLOGO À EXPERIÊNCIA EXTENSIONISTA NOS TERRITÓRIOS DO SISAL E PIEMONTE NORTE DO ITAPICURU PELA FETRAF - BA
}

\author{
FROM DIALOGUE TO EXTENSIONIST EXPERIENCE IN THE \\ TERRITORIES OF SISAL AND NORTHERN PIEMONTE OF \\ ITAPICURU BY FETRAF - BA
}

Jandeson Cardoso Silva ${ }^{1}$

Cleilton Vasconcelos Moreira ${ }^{1}$

Resumo: Este trabalho configura-se como um relato de uma experiência de extensão universitária, por meio de diálogos e atividades em comunidades rurais no estado da Bahia, nos territórios do Sisal e Piemonte Norte do Itapicuru, junto a Federação dos Trabalhadores Rurais da Agricultura Familiar da Bahia (FETRAF-BA) - Unidade de Senhor do Bonfim, BA. Objetiva-se relatar a vivência nas comunidades e propriedades rurais nos municípios de Senhor do Bonfim, Pindobaçu, Ponto Novo e Monte Santo, com foco em diferentes áreas da produção rural, abordando desde o acompanhamento efetivo de assistência técnica para agricultura, pecuária, nas melhorias ambientais e o empreendedorismo, até o processo de organização e efetivações de atividades sociais nas comunidades. O relato aborda as ações num contexto social de comunicação popular e agricultura familiar, por meio de atividades extensionistas e visitas técnicas acompanhadas, durante o estágio supervisionado curricular do curso de Engenharia Agronômica da Universidade do Estado da Bahia (UNEB). As atividades desenvolvidas propiciaram o entendimento da dinâmica de trabalho de uma organização voltada para ações de extensão. Assim, de forma conjunta, foi possível compreender as formas de abordagem e sistematização das ideias por parte dos técnicos da FETRAF-BA nas comunidades. O resultado dessa vivência refletiu no entendimento prático das técnicas de extensão e da importância da aproximação, diálogo e construção do conhecimento das atividades extensionistas para a melhoria e organização das comunidades rurais.

Palavras-chave: Extensão universitária, Comunidades rurais, Agricultura familiar.

Abstract: This work is configured as an experience of university extension through dialogues and activities in rural communities in the state of Bahia, in the territories of Sisal and Piemonte Norte de Itapicuru, through the Federation of Rural Workers in Family Agriculture in Bahia (FETRAF-BA) - Senhor do Bonfim, BA Unit. The present work relates the experience in the communities and the municipalities of Senhor do Bonfim, Pindobaçu, Ponto Novo and Monte Santo, focusing on different areas of rural production, ranging from effective monitoring of technical assistance for agriculture, livestock, with a focus on environmental improvements and entrepreneurship to the 
process of organizing and carrying out social activities in communities. The report addresses the actions in a social context of popular communication and family farming, through extension activities and accompanied technical visits, during the supervised internship. The activities developed provided an understanding of the work dynamics of an organization focused on extension actions. Therefore, jointly, it was possible to understand the ways in which FETRAF-BA technicians approach and systematize ideas in communities. The result of this experience reflected in the practical understanding of extension techniques and the importance of approaching, dialoguing and building knowledge of extension activities for the improvement and organization of rural communities.

Keywords: University Extension, Rural Communities, Family Farming.

\section{INTRODUÇÃO}

A extensão rural constitui um pilar muito importante para o crescimento e desenvolvimento socioeconômico das comunidades rurais. Além disso, norteiam o contexto humanitário e a perspectiva da conservação do ambiente em que as pessoas vivem. Os profissionais atuantes em atividades extensionistas possuem formações muito diversas: são, por exemplo, educadores, pedagogos, agrônomos, veterinários e técnicos agrícolas. De acordo com Andrade et al. (2013), para que o trabalho de extensão rural atue como processo educacional, faz-se necessário que ocorra a internalização dos conhecimentos adquiridos junto aos conhecimentos práticos já possuídos pelos agricultores, de modo que se tornam complementares.

Considerando esse contexto, o aprendizado é mútuo, pois, técnico e produtor trocam informações e, por meio de diálogos, expõem a realidade e estudam medidas para o levantamento das condições da propriedade e da comunidade, agindo de forma localizada e focada nas necessidades específicas com base nas avaliações alinhadas. Portanto, que sejam comunicadores, educadores e facilitadores do processo de trocas de experiência, de modo que a comunicação rural tenha ao seu dispor a potencialidade para favorecer o desenvolvimento agropecuário (BERNARDO \& BERNARDO, 2013; PETARLY, 2013).

A atividade relacionada à Extensão Rural "é um processo cooperativo, baseado em princípios educacionais, que tem por finalidade levar, diretamente, aos adultos e jovens do meio rural, ensinamentos sobre agricultura, pecuária e economia doméstica, visando modificar hábitos e atitudes da família, nos aspectos técnico, econômico e social, possibilitando-lhe maior produção mensal e melhorar a produtividade e, 
sobretudo, viabilize elevar a renda e, portanto, melhorando seu nível de vida" (EMATER, 2019).

A extensão rural no Brasil nasceu sob o comando do capital, com forte influência dos norte-americanos e visava superar o atraso na agricultura. Logo, havia a necessidade de instruir o povo rural, para que ele passasse a adquirir equipamentos e insumos necessários à modernização de sua atividade agropecuária. O modelo serviria para que o homem rural entrasse na rotina de mercado, produzindo mais, com melhor qualidade e maior rendimento (EMBRAPA, 2019).

Em face à observação feita, para Peixoto (2008), o termo extensão rural também pode ser entendido como uma política pública. Neste caso referimo-nos às políticas de extensão rural, traçadas pelos governos (federal, estaduais ou municipais) ao longo do tempo, através de dispositivos legais ou programáticos, mas que podem ser executadas por organizações públicas e/ou privadas.

A extensão rural tem difundido, de forma sistemática, o seu apoio a grupos de produtores, associações e cooperativas, atuando no fortalecimento das relações dos agricultores e também nos processos dialógicos, com inclusão social dos setores, destacando a importância de como participar e interagir com a Diretoria e os Conselhos. Como ressalta Melo Neto (2003), a extensão apresenta-se como uma estrada de mão dupla pela qual há uma troca entre os conhecimentos universitários e os comunitários.

Vinculada a essa concepção, a extensão rural alcança seus objetivos quando dialoga e conhece a história de cada comunidade rural, de modo que os fluxos da comunicação exercem papel determinante para a melhoria na qualidade de vida das famílias, para o fortalecimento da produção nas propriedades rurais e difusão de uma extensão rural mais próxima do agricultor familiar, valorizando os saberes, os conhecimentos e os valores locais (ALMEIDA et al., 2017; ZUIN et al., 2015; TORQUATO, 2010).

De acordo com Freire (2008), a extensão entendida através da educação deve ser pensada a partir do uso da pedagogia, iniciando pelo diálogo, pela comunicação, por uma nova relação humana que possibilite à sociedade uma construção de uma consciência crítica do mundo em que vive e concedendo-lhes a educação para a liberdade. Registra-se que, Paulo Freire já levantava (FREIRE, 1988) a crítica ao processo de extensão rural, por então apresentar um fluxo de informações unidirecional e impositivo, defendendo um processo efetivamente comunicativo, dialógico, de troca de saberes, a ser estabelecido entre o técnico e o produtor rural. 
Para Rios (2017), a história vertical do campo, essencialmente antidialógica, contribuiu para o silêncio dos camponeses e para o consequente atraso agrário. $\mathrm{O}$ autor trata em sua resenha, partindo da formulação de Freire: "Extensão ou comunicação?", a quebra dessa estrutura obsoleta acerca da compreensão sobre a extensão, e nos traz a transformação do processo de comunicação primordial para as mudanças agrárias, no qual o camponês conheça a importância do seu saber e, sobretudo o seu lugar de fala. Rios (2017) reporta ainda que o diálogo se mostra uma potente ferramenta de mutações que permite humanizar o mundo sem que aconteçam dominações ou invasões, típicas de cenários arcaicos não dialógicos.

Outro aspecto que merece destaque diz respeito ao lugar da extensão na universidade, visto que a extensão universitária possibilita a aquisição de conhecimentos que funcionam como um preparatório para a prática profissional. Como relatado por Nogueira (2005), a Extensão Universitária surgiu na Inglaterra, no século XIX, como “educação continuada" (Lifelong Education), destinada à população adulta que não tinha acesso à universidade. Foi só no início da década de 1960 que a extensão como a conhecemos hoje, indissociável do ensino e da pesquisa, tomou corpo quando surgiram ações de compromisso com as classes populares, com a intencionalidade de conscientizá-las sobre seus direitos.

Conforme discorre Gadotti (2017), vários estudos foram feitos a partir das primeiras intuições e experiências de Paulo Freire. É fundamental nos reportar a Freire, pois, suas contribuições foram valiosas na evolução na discussão sobre o conceito de Extensão. Para Freire (1975), extensão seria o ato de estender alguma coisa a/ou até alguém, exercendo uma ação que se dá, não diretamente na realidade, mas sobre e com os sujeitos que a constituem. Tomando como ponto de referência a extensão rural, o autor discorre que e conhecimento se dá de uma forma "co-participativa", a qual se efetiva na comunicação, ou seja, em uma prática dialógica (FREIRE, 1975). Registra-se, portanto, que haja algumas vertentes diferentes para o termo extensão: como processo acadêmico; como funcionalidade típica do trabalho universitário aplicado às áreas do conhecimento; e como implicação social (FARIA, 2001).

Vinculada a essa complexidade, verifica-se a construção conceitual da Extensão Universitária. No estudo de Nedison Faria, por exemplo: "Extensão universitária: desafio a uma educação conscientizadora", vê a extensão universitária como a prática pedagógica domesticadora (FARIA, 2001). Outra abordagem interessante, neste contexto, foi discutida por Jezine (2006), quando analisa a Extensão 
universitária sob a perspectiva de forma acadêmica, isto é, trabalhando a dimensão filosófico-científica; a forma assistencialista, objetivando a transmissão do conhecimento com foco voltado para sua missão social; por fim, a forma mercantilista, utilizando-se da prestação de serviços.

Em conformidade com Gadotti (2017), a Extensão Universitária pode tornar-se articuladora das políticas territoriais, mas, para isso, precisa incorporar os "saberes de experiência feitos" (Paulo Freire) das comunidades, muitas vezes silenciados, subalternizados e até marginalizados pela academia. Para o autor, a Extensão Universitária na perspectiva da Educação Popular precisa começar pela descolonização das mentes no interior das próprias universidades.

Esse fato reforça, ainda mais, que a extensão deve influenciar o ensino e a pesquisa e não ficar isolada deles, da universidade como um todo e dos anseios da sociedade, "entre-laçando" saberes e conhecimentos (SANTOS JÚNIOR, 2013). Entendida dessa forma, nos leva a compreender que na Extensão Universitária serão vivenciados aspectos da profissão, com intensa troca de experiências para propiciar reflexões sobre os impactos causados pelas atividades extensionistas na formação inicial dos discentes envolvidos (PEREIRA \& OLIVEIRA, 2019). Além disso, nos traz a compreensão do quão é possível alcançar conhecimentos específicos para se tornarem profissionais preparados para atuarem em suas respectivas áreas de formação (SILVA, 2011).

Conforme relatado no Fórum de pró-reitores de extensão das universidades públicas brasileiras (2012), a extensão universitária tornou-se o instrumento por excelência de inter-relação da universidade com a sociedade, de oxigenação da própria universidade, de democratização do conhecimento acadêmico, assim como de (re)produção desse conhecimento por meio da troca de saberes com as comunidades. Uma via de mão-dupla ou, como se definiu nos anos seguintes, uma forma de "interação dialógica" que traz múltiplas possibilidades de transformação da sociedade e da própria Universidade Pública.

A Universidade do Estado da Bahia - UNEB é uma instituição pública criada em 1983 e organizada num sistema multicampi com 29 Departamentos e com extensa atuação nos territórios de identidade da Bahia $^{1}$, engajada em diversas ações

1 Os Territórios de Identidade (TI) são a unidade de planejamento de políticas públicas do Estado da Bahia, desde o ano de 2007, na elaboração do Plano Plurianual Participativo 2008-2011 (PPA). Foi proposta uma divisão do estado em três macro-regiões: Litoral; semiárido e cerrado, que poderiam dar 
extensionistas. A PROEX (Pro-Reitoria de Extensão), órgão vinculado à Reitoria da UNEB, responsabiliza-se pela articulação e acompanhamento de programas, projetos, cursos de extensão e atividades que atentam para os objetivos institucionais e ao mesmo tempo contribuam para a materialização do que prevê a Constituição Federal, em seu artigo 207 quanto ao "princípio da indissociabilidade entre ensino, pesquisa e extensão" (RELATÓRIO DAS AÇÕES DE EXTENSÃO DA PRÓ-REITORA DE EXTENSÃO DA UNEB, 2019).

Considerando esse contexto, importa dizer que a extensão universitária interfere diretamente na realidade da comunidade em que recebe da universidade conhecimentos e informações, permitindo que participe e exponha suas opiniões deixando de ser passiva. Entre outras palavras, que só recebe e não participa, tornandose ativa (JEZINE, 2004).

Lima (2015) dá ênfase às considerações da universidade afirmando que:

Na relação universidade e comunidade, considerando a responsabilidade de uma instituição pública que sobrevive com os recursos oriundos do povo que paga seus impostos, é importante salientar ainda que "o fluxo, que estabelece a troca de saberes sistematizados, acadêmico e popular, terá como consequência: a produção do conhecimento resultante do confronto com a realidade brasileira e regional"'.

E, portanto, a fusão numa relação dialética e dialógica entre universidade e sociedade é fundamental considerando que é necessário "a democratização do conhecimento acadêmico e a participação efetiva da comunidade na atuação da Universidade".

Convém salientar que a extensão na UNEB, como prática acadêmica, busca interligar a universidade em suas atividades de ensino e pesquisa com as demandas da sociedade, por respeitar o compromisso social da universidade. Uma forma de oportunizar e experimentar essa interligação da universidade e a extensão é durante o estágio supervisionado.

No que tange o estágio supervisionado do curso de Engenharia Agronômica do Departamento de Ciências Humanas e Tecnologias (DCHT) - Campus XXII, a universidade assegura condições para o acompanhamento e orientação dos estágios além do seguro de vida. Nessas circunstâncias, prevê o Artigo 16 da Resolução n.795/2007:

origem a cinco macro-regiões a partir da sub-divisão do litoral em três áreas (Sul, Recôncavo e Norte) (SOUZA, 2008). O Governo da Bahia passou a reconhecer a existência de 27 Territórios de Identidade, constituídos a partir da especificidade de cada região. 
“Art. 16 - Caberá à UNEB disponibilizar os recursos necessários aos Departamentos, para garantirem a realização do estágio curricular dos cursos regulares.

$\S 1^{\circ}$ - A UNEB se responsabilizará pela efetivação anual do seguro de vida para os docentes de estágios dos cursos regulares cujo campo de trabalho implique em situação de risco.

$\S 2^{\circ}$ - Quando o estágio ocorrer fora da unidade sede, além dos recursos previstos no caput deste artigo, a UNEB se responsabilizará pelo seguro de vida, despesas de deslocamento e hospedagem para os docentes (quando necessário)."

Nesse contexto, a UNEB é uma instituição que fomenta e estimula as políticas de valorização da extensão universitária. Entendido dessa forma, o estágio supervisionado curricular do curso de Engenharia Agronômica oportuniza obter experiências em diversas áreas do saber, com a finalidade de ampliar os saberes e adquirir conhecimentos e habilidades na formação acadêmica e profissional. Além disso, as parcerias interinstitucionais para formalização dos campos de estágios nos cursos de bacharelado da UNEB ocorrem em conformidade com a lei de estágio 11.788/2008, com a assinatura de termos de compromisso, entre as instituições e discente, marcando o papel da universidade como mobilizadora das transformações econômicas, políticas e sociais no processo de formação acadêmica de qualidade. Quanto a isso, a UNEB postula que:

\footnotetext{
Art. $3^{\circ}$ - Os estágios serão desenvolvidos em espaços que possibilitem ao graduando, experiências crítico-reflexivas no campo profissional de sua área de formação, fundamentadas no perfil do egresso de cada curso, implicando uma permanente articulação entre as aprendizagens teórico-práticas.
}

$\S 1^{\circ}$. Os estágios deverão articular-se prioritariamente com as políticas públicas e movimentos da sociedade civil que expressem os princípios indicados no artigo $2^{\circ}$ deste regulamento;

$\S 2^{\circ}$. Os estágios deverão realizar-se, prioritariamente, nas redes públicas e em instituições e organizações da sociedade civil sem fins lucrativos, observando as demandas e especificidades locais dos cursos e departamentos.

$\S 3^{\circ}$. Os estágios deverão articular-se, prioritariamente, com programas ou projetos da UNEB e/ou das instituições parceiras, que promovam a interação entre ensino, pesquisa e extensão.

Como ressalta Corte \& Lemke (2015), é primordial apresentar aos acadêmicos aquelas atividades que promovam a reflexão não só do ponto de vista do conhecimento científico, mas, também, de seu contexto de formação e atuação, dos fundamentos da educação e da dimensão ética, política e ideológica de seu trabalho. Assim, o 
Departamento de Ciências Humanas e Tecnologias (DCHT), Campus XXII da UNEB, em suas articulações, possui convênio de estágio com órgãos, entidades ou empresas com os quais a universidade constrói parcerias, possibilitando aos seus discentes a experiência do estágio supervisionado em diversas áreas, especialmente, no âmbito da Extensão Rural, nos segmentos da produção rural e Educação do campo. Nesta perspectiva que foi constituída as parcerias da UNEB e a entidade Federação dos Trabalhadores na Agricultura Familiar do estado da Bahia (FETRAF-BAHIA).

No âmbito da educação, a FETRAF-BA carrega uma trajetória que, desde 2004, acompanha e forma, sujeitos do campo, além de articular Políticas Públicas para agricultores/as familiares com o objetivo de fortalecer e consolidar a Agricultura Familiar a partir do acesso às Políticas Públicas Rurais (ALMEIDA, 2015).

De acordo com suas estratégias de atuação, a FETRAF-BA busca a:

(...) integração de políticas públicas atuando junto ao poder público, discutindo a necessidade e disputando as prioridades dos investimentos, tanto na produção rural, quanto na instalação da infraestrutura necessária para tornar mais cidadã à vida no campo, principalmente para os jovens e mulheres (Educação, Saúde, Energia, Habitação, renda, etc). Também tem como estratégia a formação de novas lideranças, e gestores da agricultura familiar propositivo, críticos e executores de programas e políticas de desenvolvimento sustentável e solidário para agricultura familiar.

Neste sentido, a universidade e seus parceiros tem o papel de promover o contato com atividades importantes, como aquelas referentes ao manejo da água, instalação e práticas agrícolas para agropecuária e horticultura, bem como identificar as práticas agrícolas executadas nas comunidades rurais e, sobretudo, contribuir para a construção do conhecimento e para a elaboração de planos de ação dentro das famílias rurais.

À vista disso, o presente estudo configura-se como um relato de vivência da agricultura familiar de ações realizadas em comunidades rurais, junto a FETRAF-BA, especificamente no projeto "Bahia Produtiva". Assim, o objetivo do presente relato é descrever a vivência nas comunidades e propriedades rurais na Bahia, nos municípios de Senhor do Bonfim, Pindobaçu, Ponto Novo e Monte Santo, com foco em diferentes áreas da produção rural, abordando desde o acompanhamento efetivo de assistência técnica para agricultura, pecuária, nas melhorias ambientais e o empreendedorismo, até o processo de organização e efetivações de atividades sociais nas comunidades. 


\section{METODOLOGIA}

Este trabalho constitui um relato de experiência que descreve atividades de extensão realizadas em comunidades e propriedades rurais no estado da Bahia, localizadas nos municípios de Senhor do Bonfim, Pindobaçu, Ponto Novo e Monte Santo.

As ações aqui descritas fazem parte das atividades desenvolvidas na FETRAFBA, durante o estágio supervisionado curricular (março/2019 a maio/2019), do curso de Engenharia Agronômica da Universidade do Estado da Bahia (UNEB), do Departamento de Ciências Humanas e Tecnologias (DCHT), Campus XXII, localizado no município de Euclides da Cunha, Bahia.

As intervenções nas comunidades foram planejadas e desenvolvidas por meio de reuniões com os técnicos da organização, bem como a participação em atividades de levantamento da problematização e observação da realidade. A partir disso, foram desenvolvidas atividades de elaboração de um plano de intervenção, com intuito de responder às necessidades levantadas para cada realidade local, para sua execução e posterior avaliação. Mediante acompanhamento junto à equipe técnica da FETRAF-BA (constituídos por engenheiros agrônomos, técnicos agrícolas e pedagogos), foram executadas diversas ações e discussões nas respectivas microrregiões, possibilitando vivenciar a rotina diária destes profissionais técnicos locais, ampliando conhecimentos a respeito da FETRAF-BA e serviços oferecidos pela mesma, como prestadora de serviços de Assistência Técnica e Extensão Rural (Ater). Por meio do serviço de Ater, enquanto política pública, foram realizadas algumas visitas para identificar necessidades e potencialidades de cada família (IEA, 2016). Entre outas atividades, foi possível levar até os produtores assistidos no projeto Bahia Produtiva conhecimentos e assuntos essenciais, visando à melhoria do desempenho do empreendimento, através de visitas, apresentações e palestras.

\section{ATIVIDADES REALIZADAS PELOS PROJETOS DE EXTENSÃO}

A Federação dos Trabalhadores na Agricultura Familiar do estado da Bahia (FETRAF-BAHIA) é uma organização sindical que nasceu em 2004 como o resultado de uma longa caminhada repleta de lutas, reuniões e reflexões entre diversos autores das 
organizações sociais. A FETRAF-BA surgiu das experiências e apoio de diversas organizações não governamentais a partir da necessidade de construir "um novo sindicalismo" e se concretizou no I Congresso da Agricultura Familiar na Bahia, realizado no período de 14 a 16 de abril de 2004, no município de Simões Filho/BA.

Desde então, a FETRAF-BAHIA desenvolve ações voltadas para a organização, ação e formação do trabalhador rural. Desenvolvem também ações voltadas para a construção de conhecimentos sobre o trabalho rural, educação do campo, desenvolvimento sustentável e solidário, fortalecimento das lutas pelo acesso à terra e políticas públicas para o meio rural, combatendo, assim, a discriminação e a exclusão dessa importante classe social.

Com sede na cidade de Salvador, atualmente tem uma atuação em mais de 90 municípios, expandindo a cada dia o seu espaço de atuação a partir da articulação com as associações comunitárias, sindicatos rurais, cooperativas e outras entidades e instituições parceiras.

Sua missão é consolidar a organização sindical da agricultura familiar na diversidade organizativa dos sindicatos, cooperativas, associações e grupos pautados no desenvolvimento econômico e melhoria da vida social. A FETRAF-BA possui formas importantes de ações e estratégias, como a organização sindical, propiciando um conjunto de modificações profundas nos sindicatos, através de ações articuladas com os mesmos, tornando-os fortes e com grande poder de mobilização, além do diálogo com outros atores da sociedade. Outra estratégia é o desenvolvimento rural com projetos economicamente sustentáveis, com sistemas cooperativos de crédito, produção e agroindustrialização dos produtos da agricultura familiar, disputando e criando alternativas de mercado e do comércio justo e solidário.

É nessa perspectiva que Lima et al. (2014) destaca a importância do contato direto com as lideranças locais da comunidade, de modo que as estratégias de comunicação e mobilização social no desenvolvimento das atividades são instrumentos imprescindíveis aos extensionistas junto aos agricultores.

As atividades desenvolvidas durante o estágio foram definidas mediante a participação nas reuniões com toda a equipe da FETRAF-BA que estavam vinculadas ao projeto 'Bahia Produtiva', conduzidas pela coordenadora da unidade, a fim de transmitir as devidas informações. O 'Bahia Produtiva' é um projeto do Governo do Estado da Bahia, executado pela Companhia de Desenvolvimento e Ação Regional CAR, empresa pública vinculada à Secretaria de Desenvolvimento Rural - SDR, a partir 
de Acordo de Empréstimo firmado entre o Estado e o Banco Interamericano de Reconstrução e Desenvolvimento (Banco Mundial).

Por meio destas reuniões, na ocasião, foram pensadas as intervenções, que, por sua vez, foram desenvolvidas a partir da observação da realidade, da identificação do problema, seguida da elaboração de um projeto de intervenção capaz de responder às necessidades levantadas para aquela comunidade.

Nos encontros realizados no escritório, foram discutidos os planejamentos das atividades. Nesse momento, foram promovidas as discussões sobre as atividades que iriam ser realizadas na semana. Em cada visita, seja coletiva ou individual, procedeu-se à elaboração de um relatório.

Dentre as atividades realizadas durante o estágio, a elaboração dos relatórios constituiu-se em uma das atividades mais importantes pertinentes à descrição das visitas. O relatório foi utilizado para a comprovação das visitas, encontros e atividades realizadas nas comunidades; logo continha informações estruturadas em: 1 Identificação e 2 - Conteúdo e Estrutura. Sendo assim, continha a introdução, que descrevia as atividades, e abordagem de forma ampla o contexto da visita e os seus objetivos, apresentando, ainda, as circunstâncias que levaram a realização dessa visita. Nos resultados alcançados, foi necessário discorrer sobre quais os resultados obtidos ao final da visita, podendo ser positivos ou negativos. Por fim, apresentavam os encaminhamentos, que, a partir dos resultados obtidos, seriam necessários, caso houvesse alguma recomendação, seriam agendados uma próxima visita ou encontro, de modo que também poderia ocorrer via solicitação do beneficiário.

Com efeito, é importante estabelecer processos rigorosos para a inclusão de dados no relatório do extensionista, pois, fazem parte das práticas do escritório para lograrem os resultados esperados. Para Mafra (2006), planejar a comunicação de forma estratégica contribui para promover os vínculos entre os públicos e os projetos de mobilização social. Sobre as observações do técnico, era preciso construir uma observação pessoal e técnica da atividade realizada, levando-se em consideração todos os aspectos da visita realizada e, por fim, realizar a inclusão do registro fotográfico (quatro fotos) para comprovar perante aos órgãos de fiscalização a realização da atividade.

Semanalmente foram realizadas visitas técnicas agropecuárias para atender às necessidades que surgiam nos empreendimentos nas propriedades rurais, a exemplo da assistência técnica para agricultores e pecuaristas. Essas visitas ocorreram da seguinte 
forma: visitas individuais, que consistia na ida até a casa de um beneficiário para a realização da assistência técnica na unidade produtiva, e visitas coletivas, as quais, obrigatoriamente, constituíam-se da presença de, no mínimo, três beneficiários, e foi realizada no empreendimento adquirido por meio do projeto Bahia Produtiva, ou em local comum a todos os moradores da comunidade.

Já nos encontros comunitários, as atividades foram realizadas durante todo o dia, pois exigiam uma carga horária mínima de seis horas. Nessas ações, proferimos palestras voltadas ao empreendimento e, na ocasião, também realizamos apresentações que incluíram amostras de vídeos motivacionais, interativos e didáticas. Nessa concepção de estratégia de comunicação e mobilização, do ponto de vista de Lima et al. (2014), os materiais como banners e folhetos, tem sido utilizados para incentivar e estimular a participação dos agricultores no âmbito de suas próprias atividades produtivas.

Além disso, durante as reuniões coletivas, tivemos a possibilidade de integrar os conhecimentos compartilhados nas atividades profissionais junto às comunidades. Como reflexo dessa situação, é possível relacionar com argumentos de Morin (2007), que aponta que a compreensão significa um fenômeno que permite entender as pessoas como sujeitos com valores, costumes e trajetórias. Isso permitiu inferir que as ações extensionistas não se restringem apenas à prestação de serviços à comunidade. Dessa forma, com essas percepções, foi possível notar a consistência teórica e operacional que estrutura o trabalho dos profissionais do processo de extensão rural. Cabe ressaltar ainda que muitas atividades se constituíram como mecanismo de aproximação com a comunidade, propiciando momentos interativos nas reuniões, construindo um elo de confiança e credibilidade pelo trabalho de assistência técnica.

\section{O AGENTE COMUNitário RURAL (ACR) E AGENTE COMUNitário APÍCOLA (ACA)}

Conforme o novo contexto do serviço da Assistência Técnica e Extensão Rural (Ater), com base na Lei 12.372 de 23 de dezembro de 2011, entende-se que as vocações regionais e locais são de extrema importância para o desenvolvimento sustentável das atividades agrícolas e não agrícolas realizadas nas comunidades. Insere-se, nesse contexto, o manejo adequado dos recursos naturais, a partir da utilização de insumos naturais e adoção de técnicas de base agroecológica, promovendo a utilização de 
sistemas sustentáveis de produção, com ênfase nas questões ambientais e no uso da água, oferecendo um alimento mais saudável, sem perder em produtividade nem retorno econômico para as famílias.

Vinculada a essa concepção, o projeto Bahia Produtiva, em parceria com outras entidades, tinha como planos de ações um serviço de assessoramento técnico comunitário, com capacitação da mão-de-obra local para oferecer uma oportunidade para permanência do jovem no campo. Durante as participações nesses encontros, como proposta, foi definido que um jovem da comunidade seria indicado e contratado (a partir da análise do seu perfil, habilidades e suas afinidades) para assessorar as famílias beneficiárias nos subprojetos, mediante treinamento e capacitação, e como "Agente Comunitário Rural - ACR" teria a função de acompanhar/assessorar as famílias e multiplicar conhecimentos adquiridos em capacitações e experiências nas unidades familiares.

Desse modo, as atribuições do ACR envolviam: apoiar as ações locais do Bahia Produtiva, difundindo conhecimentos e orientações da rede de ATER implantada por território de identidade; atuar na condução dos problemas locais dos beneficiários para a referida rede e responder às dúvidas e demandas de conhecimento técnico que possam ser replicados por um agente local, a critério da rede de ATER; promover o apoio na organização e gestão dos aspectos produtivos e operacionais, de agregação de valor e de comercialização das beneficiadas.

Todas as comunidades assessoradas pela FETRAF-BA, no projeto, tinham um ACR ou ACA, caso a finalidade fosse apicultura. Assim, realizamos visitas e encontros, a fim de alinhar as atividades desenvolvidas por esses agentes e esclarecer dúvidas, bem como dar sugestões e realizar o acompanhamento das atividades desenvolvidas.

Outras ações que merecem ser destacadas neste trabalho incluem a participação no intercâmbio realizado na cidade de Serra Preta - BA, onde foi possível a organização de um evento junto aos técnicos da FETRAF-BA. Em função do empreendimento daquela região já ter sido instalado (instalação para criação de galinhas), este serviu de modelo para as outras localidades que possuíam o mesmo empreendimento. Foi realizada a atividade de intercâmbio com as comunidades de Salinas e Pereiros, localizadas no município de Senhor do Bonfim - BA, por possuir empreendimentos semelhantes aos de Serra Preta. Com isso, os participantes dialogaram entre si, possibilitando, portanto, presenciar o sucesso daquele empreendimento e, assim, incentivar as demais comunidades no planejamento, bem como dialogar sobre os 


\section{REALIZZẠÇăO}

cuidados para manejo dos seus criatórios de galinhas em suas respectivas unidades produtivas.

É importante destacar também outras atividades relevantes, como a participação na realização do Dia de Campo em duas comunidades beneficiadas com projetos do Bahia Produtiva. Foi possível contribuir e participar desse evento na comunidade de Curadeira, abordando, inclusive, o tema sobre os canteiros econômicos, tendo como principal objetivo discutir os aspectos acerca da eficiência do uso sustentável da água (Figura 1A).

Na comunidade de Quicé - BA envolveram as atividades de plantio e implantação da cultura da Palma. Na ocasião, foi possível, ainda, abordar o tema sobre o plantio de palma adensada, visando otimização no método de plantio no uso da área (Figura 1B).
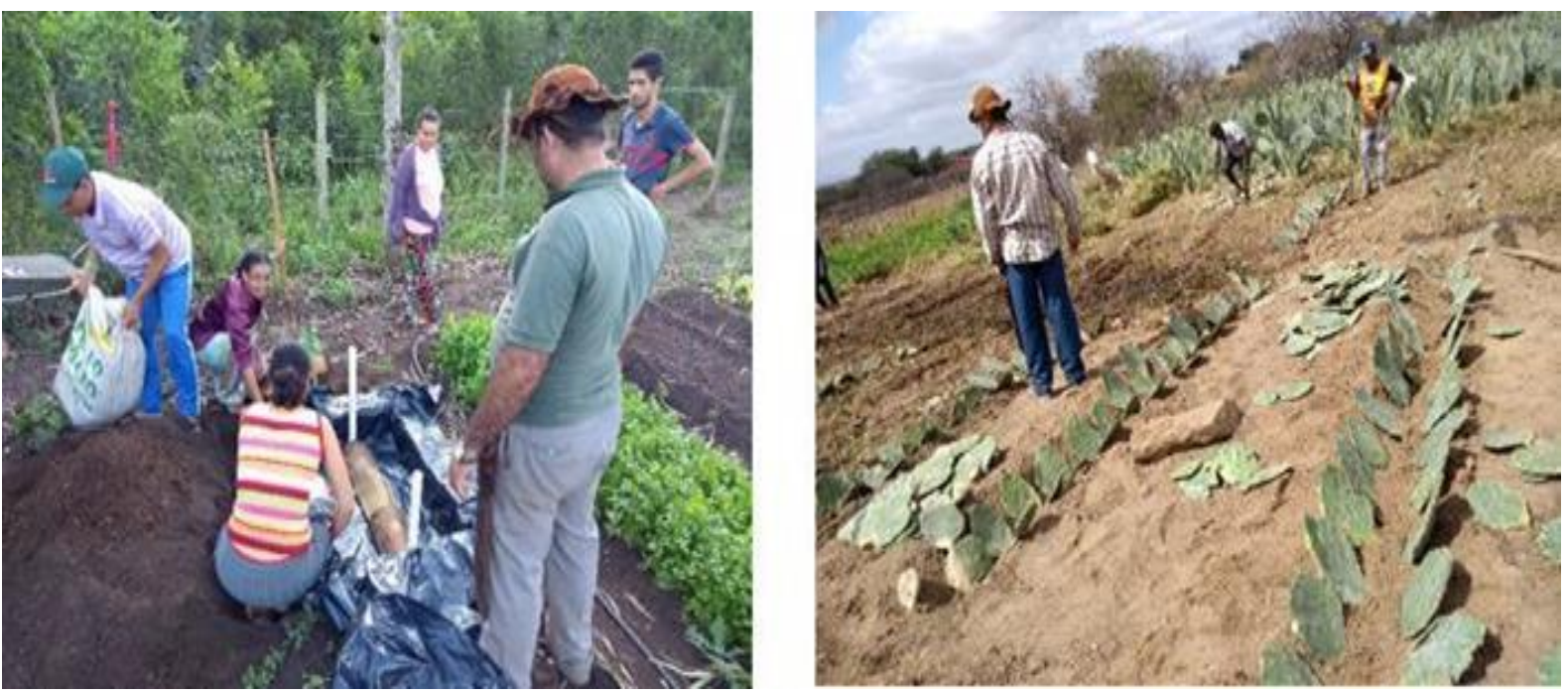

Figura 1. A) Dias de campo realizados na comunidade de Curadeira e B) Quicé na Bahia, visando orientar os beneficiários para a otimização do uso dos recursos para os seus respectivos empreendimentos.

Durante a experiência extensionista, foi possível realizar um seminário como atividade inclusiva na comunidade de Lagoa do Peixe. O tema abordado foi economia solidária, voltada especificamente para essa comunidade, de modo que essa ação permitiu um diálogo produtivo sobre experiências com foco em atividades econômicas de produção, oferta de serviços, comercialização, finanças e consumo baseado na democracia e na cooperação.

Para Thiollent (2011) os trabalhos participativos nas práticas de Extensão Rural podem contribuir para a valorização das potencialidades e capacidades de organização 
coletiva desses agricultores. Essas ações incluem as reuniões, seminários, entrevistas coletivas e aprendizagem conjunta na solução dos problemas identificados.

Lima et al. (2014) dão ênfase às estratégias de comunicação abordadas afirmando:

\begin{abstract}
Na relação técnico/agricultor, o papel do líder local pode ser de fundamental importância para o sucesso ou insucesso das ações a serem desenvolvidas na comunidade rural, pois, ao mesmo tempo em que passam certa "segurança" aos extensionistas para se trabalhar junto aos agricultores, pode influenciar também, na participação de forma mais ativa dos agricultores nas atividades propostas.
\end{abstract}

\title{
AÇÕES E EMPREENDIMENTOS NAS COMUNIDADES
}

A partir do acompanhamento do edital do projeto Bahia Produtiva, foi possível identificar os territórios, municípios e comunidades que foram beneficiadas com diversos empreendimentos. Nesse projeto, alguns empreendimentos foram definidos numa etapa anterior, mediante a avaliação da entidade prestadora de serviço naquela comunidade. Para isso, foram levadas em consideração as práticas agrícolas que já vinham sendo desempenhadas nas comunidades.

As comunidades assistidas pela FETRAF-BA estão presentes em dois territórios: Piemonte Norte do Itapicuru, com atuação nos municípios de Senhor do Bonfim, Pindobaçu, Ponto Novo e no território do Sisal, este no município de Monte Santo.

De acordo com os empreendimentos conquistados pelas comunidades, na cidade de Senhor do Bonfim - BA, as comunidades envolvidas nas ações do projeto foram: Curadeira, que foi comtemplada com o empreendimento kit de irrigação, viabilizando, portanto, potencializar a produção agrícola daquela comunidade. $\mathrm{Na}$ comunidade Lagoa do Peixe, a partir das intervenções nos encontros, o empreendimento conquistado foi referente ao beneficiamento para Poupa-de-Frutas, o que viabilizou um plano de restauração de uma estrutura física com equipamentos que possam produzir as polpas.

Para a comunidade de Pereiros e Salinas, as ações envolveram a construção de instalações de um galinheiro, além da aquisição de galinhas da raça ISA Brown para as famílias beneficiárias. Já na comunidade de Quicé, com histórico de grande potencial na produção de leite, o empreendimento foi a restruturação do laticínio, viabilizando aos 
produtores uma estrutura que garantirá melhoria na cadeia produtiva, no sistema de produção e na qualidade no produto.

$\mathrm{Na}$ cidade de Pindobaçu, a comunidade beneficiada foi Ouricuri. Foi viabilizada para os beneficiários a instalação de um galinheiro nas suas propriedades, semelhante aos das comunidades de Senhor do Bonfim, assim como a aquisição de galinhas da raça ISA Brown.

Em Ponto Novo, o empreendimento contemplou a apicultura, de modo que os beneficiários receberam kits contendo caixas, cera, quadros, equipamento de proteção individual (EPI), entre outros acessórios relativos à criação de abelhas.

$\mathrm{Na}$ comunidade de Angico, localizado no município de Ponto Novo, os beneficiários, por meio de um projeto constituído somente por mulheres, foram contemplados com o empreendimento de uma cozinha comunitária.

Esse empreendimento viabilizará a geração de produtos que poderão ser comercializados em feiras livres próximas. Mediante as orientações técnicas da FETRAF-BA, espera-se que a produção agrícola possa ser potencializada e, consequentemente, tornar-se viável.

A partir de tais constatações, foi possível, por meio de diálogos, sugestões sobre diversos temas e ações de orientação, tais como apresentações orais nos encontros, contribuir para que essas produtoras e cozinheiras pudessem colocar as ideias em prática e tornar o empreendimento consolidado. No município de Monte Santo, as comunidades comtempladas foram Boa Vista e Salgado, caracterizadas pelo perfil pecuário. Como já possuíam empreendimentos relacionados à área; foram, então, adquiridos exemplares de ovinos e caprinos aos seus beneficiários.

A FETRAF-BA dialoga com os beneficiários, no sentido de permitir que solicitem ou sugiram alguns materiais complementares que possam ajudar a fortalecer o empreendimento adquirido. Dessa forma, foi possível acompanhar as atividades e realizar orientações para melhorias na unidade produtiva, a fim de potencializar a atividade financeira daquelas famílias.

As comunidades de Muquém e São Pedro foram contempladas com barracas comunitárias para que os beneficiários pudessem comercializar os produtos gerados na comunidade, proporcionando renda. A FETRAF-BA, enquanto prestadora de assistência técnica, estava incumbida de orientar, sugerir e interferir de modo positivo para que os beneficiários pudessem ter sucesso nas atividades financeiras que foram desenvolvidas. 
Nessas vivências extensionistas, foram incluídas as atividades de mobilização dos grupos que produziam artesanato, a partir dos diálogos e levantamento de alternativas e canais de escoamento dos produtos artesanais, oriundos das comunidades realizando, assim, algumas apresentações orais sobre temas relacionados ao empreendimento.

Os empreendimentos nas comunidades é uma tentativa governamental de estimular as pessoas para que possam produzir e, consequentemente, gerar fonte de renda, contribuindo, assim, para o crescimento social e financeiro daquela comunidade.

Em conformidade com Oliveira et al. (2015), ressalta-se que é imprescindível que órgãos responsáveis pela extensão rural, como: instituições públicas e privadas, Universidades, SENAR, FETRAF-BA, contribuam na elaboração e promoção de cursos de capacitação de práticas agrícolas sustentáveis, por meio das ferramentas de diálogos para os trabalhos junto a comunidades rurais, estreitando a relação extensão e ensino tornando um ambiente privilegiado de mobilização social na construção de cidadania.

\section{CONSIDERAÇÕES FINAIS}

As experiências vivenciadas nos aproximam da realidade, nos revelam o papel do extensionista e sua importância para o meio rural. Em face das informações relatadas, decorrente de nossa experiência, é notório que o estágio é um catalisador do conhecimento, e constitui uma excelente articulação do ensino, pesquisa e extensão. Assim, as intervenções possibilitaram a compreensão da integração de conhecimento técnico e experiências pessoais, numa perspectiva mais dialogal, reflexiva e criativa. Conforme argumenta Silva e Herrera (2013), torna-se imprescindível repensar as práticas de extensão rural através da sincronização das pesquisas e experiência, entre as teorias e metodologias com base na agroecologia e, consequentemente, do desenvolvimento sustentável para as práticas de extensão rural.

Notadamente, apesar de crescente, a participação do Engenheiro Agrônomo e do Técnico agrícola nas práticas extensionistas ainda é bastante distante e pontual, o que deveria ser mais explorada tanto pelas empresas competentes quanto pelo próprio profissional, que, muitas vezes, não encontra estímulos e condições adequadas em termos econômicos e estruturais para permanecerem atuação como extensionista. Ademais, o baixo número de técnicos para dar orientação, a falta de envolvimento de alunos em estágios e pesquisas no âmbito da extensão universitária explica essa situação. Por isso é fundamental investigar e mitigar a introdução de tecnologias; a 
valorização do extensionista, que tem um importante papel na troca de conhecimentos básicos para o agricultor familiar, assim como a valorização da extensão universitária, pois, é evidente o papel da universidade no desenvolvimento da agropecuária local para promover práticas integradas entre várias áreas do conhecimento. Dessa forma, o meio agrícola, a pesquisa, ensino e extensão estão intimamente ligados e a integração desses eixos é uma oportunidade de desenvolvimento socioeconômico. Assim, com essas experiências, observou-se que o conhecimento da teoria precisa dialogar com a prática. Por fim, salienta-se que as ações desenvolvidas junto a FETRAF-BA propiciaram o crescimento e amadurecimento profissional a partir das intervenções transformadoras nas comunidades rurais na melhoria da qualidade de vida das famílias.

\section{REFERÊNCIAS}

ALMEIDA, E. N.; BRIENZA JUNIOR, S.; XIMENES, T.; DA POÇA, R. R. O modelo de assistência técnica e extensão rural do Proambiente: uma Inovação na Agroecologia. In.: Congresso da Sociedade Brasileira de Economia, Administração e Sociologia Rural - Inovação, extensão e cooperação para o desenvolvimento, 55, 2017, Resumos... Santa Maria - RS: SOBER, Universidade Federa de Santa Maria - RS. 2017.

\section{ALMEIDA, V. L. O papel da FETRAF-BA no aporte de políticas aos agricultores} de base ecológica de Presidente Tancredo Neves-BA, 2015. 125 f. Dissertação (Mestrado em Desenvolvimento e Meio Ambiente) - Universidade Federal de Sergipe, São Cristóvão-SE, 2015.

ANDRADE, A. A. X. de.; FERREIRA NETO, J. A.; OLIVEIRA, M. L.R. de.; SILVA, G. B.; MOREIRA, D. C. Do difusionismo às novas perspectivas da extensão rural: Ações extensionistas em Ibitiara-BA. Revista Uniara, v.16, n.2, 2013.

BERNARDO, C. H. C.; BERNARDO, R. Gestão da Comunicação para o Agronegócio. Revista Cambiassu. UFMA n. 12. p. 43 - 55, 2013.

BRASIL. Universidade do Estado da Bahia. Resolução Consepe n. 795/2007. Regulamento de Estágio da UNEB. 2007. Diário Oficial da União, (Publicada no D.O.E. de 21-09-2019, pág. 36). Disponível em: <https://portal.uneb.br/prograd/wp- 
content/uploads/sites/63/2019/10/2016-consepe-Res.-Regulamento-de-Estagio.pdf >.

Acesso em: 27 maio 2020.

CORTE, A. C. D.; LEMKE, C K. O estágio supervisionado e sua importância para a formação docente frente aos novos desafios de ensinar. In: Congresso Internacional de Educação, 12, 2015. Puc-Paraná. Resumos... Puc-Paraná: EDUCERE, 2015.

EMATER. Histórico da extensão rural oficial: Uma história de compromisso com a agricultura do Paraná. Instituto Paranaense de Assistência Técnica e Extensão Rural. 2019. Disponível em:

<http://www.emater.pr.gov.br/modules/conteudo/conteudo.php?conteudo=43> .Acesso em: 12 ago. 2019.

Empresa Brasileira de Pesquisa Agropecuária (Embrapa). Considerações sobre a extensão rural no Brasil. Disponível em: https://www.infoteca.cnptia.embrapa.br/infoteca/bitstream/doc/809997/1/ADM077.pdf> . Acesso em: 17 ago. 2019.

FARIA, D. S. Construção Conceitual da Extensão Universitária na América Latina. Brasília: Universidade de Brasília, 2001, p177-185.

FETRAF-BA. Desenvolvido pela Assessoria de Comunicação da Federação dos Trabalhadores da Agricultura Familiar no estado da Bahia. Apresenta informações gerais sobre a instituição. Disponível em: < http://www.fetrafba.org.br>. Acesso em: 12 ago. 2019.

FREIRE, P. Educação como prática da liberdade. 31 ed. Rio de Janeiro: Paz e Terra, 2008. 150 p.

Extensão ou Comunicação?. Rio de Janeiro/RJ, Ed. Paz e Terra, 93 p.

1988.

Extensão ou Comunicação? $2^{a}$ ed. Rio de Janeiro. Editora Paz e Terra, 1975. 93p. 
Fórum de pró-reitores de extensão das instituições públicas de educação superior brasileiras. Política Nacional de Extensão Universitária. Gráfica da UFRGS. Porto Alegre, RS, 2012. Disponível em <https://portal.uneb.br/proex/wpcontent/uploads/sites/62/2018/02/2012-07-13-Politica-Nacional-de-Extensao.pdf> Acesso em: 27 maio 2020.

GADOTTI, M. Extensão universitária: Para quê? Brasil: Instituto Paulo Freire, 2017. INSTITUTO DE ECONOMIA AGRÍCOLA - IEA. Assistência Técnica e Extensão Rural no Brasil: um pouco de sua história. Análises e indicadores do Agronegócio, v. 11, n. 5, 2016.

JEZINE, E. A Crise da Universidade e o Compromisso Social da Extensão Universitária. João Pessoa - PB: Editora Universitária, p. 332, 2006.

As Práticas Curriculares e a Extensão Universitária. In: Congresso Brasileiro de Extensão Universitária, 2, 2004. Belo Horizonte, MG. Anais... Disponível em: 〈http://www.ufmg.br/congrext/Gestao/Gestao12.pdf>. Acesso em: 16/05/2020.

LIMA, A. S. M. Extensão universitária da UNEB: A experiência do Projeto vivências e atuação sociocultural de estudantes em comunidades. In: Congresso Internacional de Educação, 12, 2015. Puc-Paraná. Resumos... Puc-Paraná: EDUCERE, 2015.

LIMA, F.A.X.; VARGAS, L. P.; SOUZA, G.M.B.; JOTA, T. A .F.\& WIZNIEWSKY, J. G. Extensão rural, comunicação e mobilização social: experiências do IPA junto aos agricultores familiares de Pernambuco. Sociedade e Desenvolvimento Rural. v. 8, n. 2, 2014.

MAFRA, Rennan. Entre o espetáculo, a festa e a argumentação - mídia, comunicação estratégica e mobilização social. Belo Horizonte: Autêntica, 2006.

MELO NETO, J. F. Extensão universitária e produção do conhecimento. Revista da ADUF/PB, n. 9, p. 13-17, 2003. 
MORIN, E. As duas globalizações: complexidade e comunicação uma pedagogia do presente. 3. ed. Porto Alegre: Sulina, EDIPUCRS, 2007.

NOGUEIRA, M. D. P. Políticas de extensão universitária brasileira. 1 ed. Belo Horizonte, Editora UFMG, 2005.

OLIVEIRA, M. L. R.; SOARES, M. B. Diálogos uma experiência de extensão em duas comunidades rurais de Viçosa-MG. Revista Ciência e Extensão. v.11, n.1, p.131-138, 2015.

PEREIRA, A. D. S., \& OLIVEIRA, A. M. de. A Experiência extensionista no estágio supervisionado de química: o projeto de integração escolar. Revista Brasileira de Extensão Universitária, v. 10, n.3, p. 131-139, 2019.

PEIXOTO, M. Extensão rural no Brasil: uma abordagem histórica da legislação. Senado Federal: Textos para Discussão, no 48, 2008. 27 p.

PETARLY, R. R. Assistência técnica e extensão rural para quê? O caso da cooperativa agropecuária de Patrocínio. 2013. 86 f. Dissertação - Programa de PósGraduação em Extensão Rural, Universidade Federal de Viçosa. Departamento de Economia Rural, Viçosa, MG, 2013.

RIOS, A. Resenha: extensão ou comunicação? Revista Dialogos: extensão ou comunicação? diálogos para a prática educativa nos contextos de emancipação, v.21, n.1, 2017.

SANTOS JÚNIOR, A. L. A extensão universitária e os entre-laços dos saberes. 2013. 248 f. Tese de Doutorado - Programa de Pós-Graduação em Educação, Universidade Federal da Bahia, Faculdade de Educação, Salvador, BA, 2013.

SILVA, A. R. A Contribuição da Extensão na Formação do Estudante Universitário. Dissertação (Mestrado em Educação) - Universidade Católica de Brasília: Distrito Federal, 97 f., 2011. 


\section{REALIZZAÇĂ $\odot$}

SILVA, M. C. do C; SILVA, L. M. S, HERRERA, J. A. Avaliação de sustentabilidade de agroecossistemas orgânicos. In: Congresso Brasileiro de Agroecologia - Porto Alegre/RS, 8, 2013.

THIOLLENT, M. Metodologia da pesquisa-ação. 18. ed. São Paulo: Cortez, 2011.

TORQUATO, G. Tratado de Comunicação Organizacional e Política. São Paulo: Editora Cengage Learning, 2010.

UNEB. Estatuto da Universidade do Estado da Bahia. Resolução CONSU nº83/2011(D.O.E. 19/20-11-2011), homologada pelo Decreto n 13.664 , de 07-022012 (D.O.E. 08-02- 2012).

UNEB. Relatório das ações de extensão da Pró-Reitora de extensão da UNEB, 2019. Disponível em: <https://portal.uneb.br/proex/wpcontent/uploads/sites/62/2020/02/Relat\%C3\%B3rio-PROEX-2019.pdf> Acesso em: 20 ago. 2020 .

ZUIN, L. F. S.; ZUIN, P. B.; QUEIROZ, T. R. Gestão, inovação e sustentabilidade nos agronegócios. In ZUIN, L. F. S.; QUEIROZ, T. R (Coords). Capítulo 1. São Paulo: Saraiva 2015. 